\section{Speed up reprocessing}

W\&H aims to help clinicians optimise their handpiece maintenance procedures with the Assistina TWIN, which features two chambers that can be used alternately to speed up reprocessing.

The Assistina TWIN nebulises the oil to produce a dispersible mist that is discharged through the handpiece at high pressure. This not only removes contamination from within the instrument, but also ensures even the most inaccessible parts are consistently coated. Spray channels can be cleaned and components oiled in just ten seconds per handpiece, enabling you to process up to 360 instruments per hour.

Discover why rotational lubrication has become a thing of the past with the Assistina TWIN from W\&H.

To find out more visit www.wh.com/ en_uk, call 01727874990 or email office.uk@ wh.com.

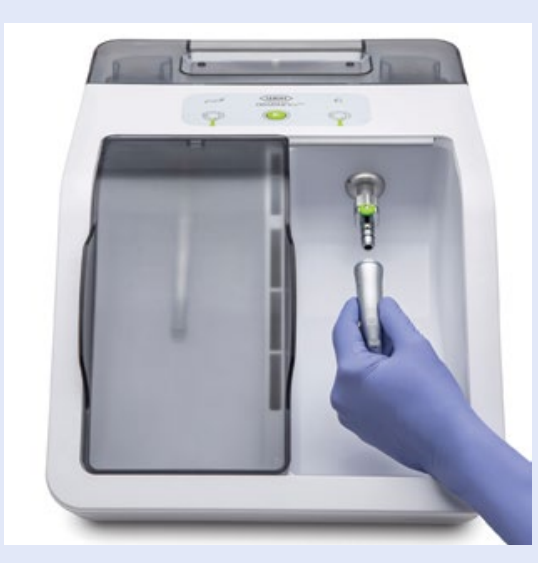

\section{The devil's in the detail}

Among the many benefits of the Cavex Cream alginate is its ability to replicate even the finest features with $5 \mu \mathrm{m}$ detail reproduction. Not only does this lead to accurate impressions for improved restorations and prostheses, but the patient will also appreciate the reduced need for retakes.

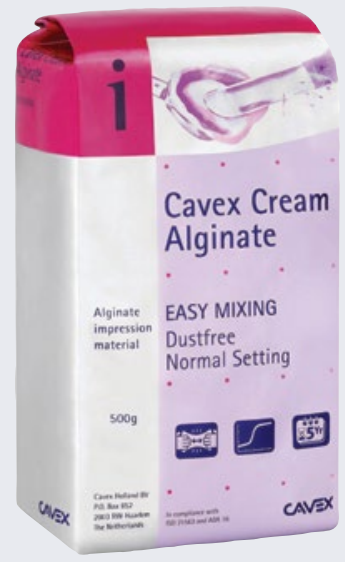

Cavex Cream is easy to mix and exhibits high tear strength and elasticity, making it ideal for multiple casting. Plus, it maintains dimensional stability for up to two days, giving sufficient time for impressions to be cast without any complications.

Available with normal or fast setting properties, Cavex Cream is distributed by J\&S Davis and can be ordered direct or from your normal supplier.

For more information on the industry-leading products available from J\&S Davis, visit www.js-davis. co.uk, call 01438747344 or email jsdsales@js-davis.co.uk.

\title{
Long-lasting restorations made easy
}

GC UK is preparing to showcase the very latest in innovative aesthetic restorative materials on Stand A32 at the BDC\&DS 2020.
With its incredible strength and easy application, everX Flow flowable composite is the go-to product for all restorations in need of a strong core. everX

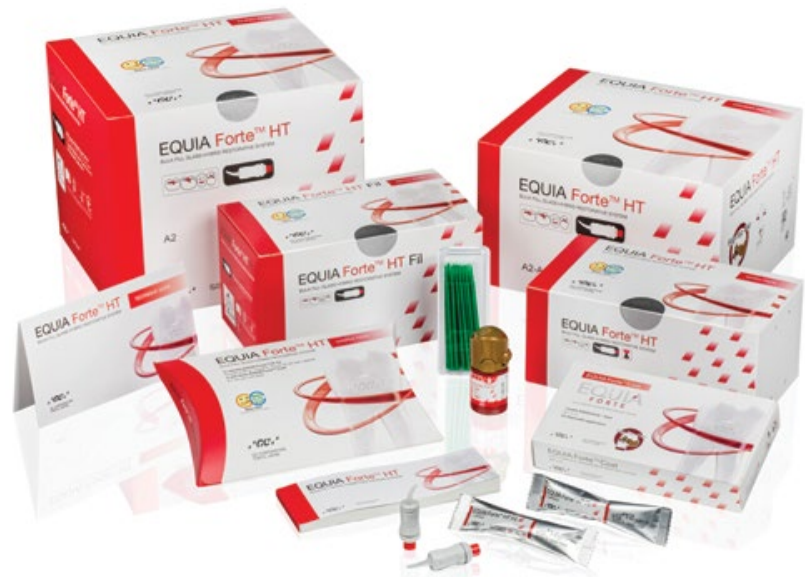

Pushing the boundaries of glass hybrid technology, discover why GC EQUIA Forte HT is the ideal partner for posterior restorations. EQUIA Forte HT's mix of glass particle sizes creates a strong, nonsticky material that is perfect for bulk-fill placement, even in load-bearing Class II restorations.

EQUIA Forte HT offers:

- Increased translucency

- High compressive strength improving durability and wear resistance

- No etching is required, relying instead on chemical adhesion that minimises the risk of post-operative sensitivity.

EQUIA Forte HT has been designed to make daily restorative work as simple and efficient as possible whilst at the same time delivering excellent aesthetic outcomes.
Flow has been designed to replace dentine and reinforce even the largest restorations while simultaneously preventing them from cracking.

Offering high wear resistance and superb aesthetics, everX Flow stands apart for its excellent fracture toughness, close to that of dentine, due to the high amount of short fibres strongly bonded to the resin matrix. Its thixotropic viscosity allows it to adapt perfectly to the cavity floor without slumping, even when placed in upper molars.

To find out more about GC's restorative innovations and to take advantage of exclusive TDS special offers, visit the GC UK team on Stand A32. For more information contact GC on 01908218999 , email info.uk@gc.dental or visit www. gceurope.com. 